\title{
Novoamauromine and ent-Cycloechinulin: Two New Diketopiperazine Derivatives from Aspergillus novofumigatus
}

\author{
Kazuki Ishikawa, ${ }^{a}$ Tomoo Hosoe, ${ }^{*}, a$ Takeshi Itabashi, ${ }^{a}$ Daigo Wakana, ${ }^{a}$ Kayoko Takizawa, ${ }^{b}$ \\ Takashi YAGUCHI, ${ }^{b}$ and Ken-ichi KAWAI ${ }^{a}$ \\ ${ }^{a}$ Faculty of Pharmaceutical Sciences, Hoshi University; Ebara 2-4-41, Shinagawa-ku, Tokyo 142-8501, Japan: and \\ ${ }^{b}$ Research Center for Pathogenic Fungi and Microbial Toxicoses, Chiba University; Inohana 1-8-1, Chuo-ku, Chiba \\ 260-8673, Japan. Received October 10, 2009; accepted February 26, 2010; published online March 4, 2010
}

Two new diketopiperazine metabolites, novoamauromine (1) and ent-cycloechinulin (2) have been isolated from Aspergillus novofumigatus CBS117520. The structures of 1 and 2 were established on the basis of spectroscopic and chemical investigation, including a detailed comparison of the spectroscopic and physico-chemical data of amauromine (3) and cycloechinulin (4).

Key words Aspergillus novofumigatus; novoamauromine; ent-cycloechinulin; diketopiperazine

The fungus Aspergillus fumigatus is known as an important human pathogen and a strain that produces many secondary metabolites. The fungus Aspergillus novofumigatus CBS117520 was isolated originally as A. fumigatus from Equadorian soil in 1965. In 2005, Hong et al. re-identified it as the new Aspergillus sp., closely related to A. fumigatus. ${ }^{1)}$ We have isolated two new diketopiperazines, novoamauromine (1) and ent-cycloechinulin (2), along with epiaszonalenins $\mathrm{A}$ and $\mathrm{C},{ }^{2)}$ and helivolic acid, ${ }^{3-5)}$ from the methanolic extract of this fungus cultivated on rice using a thin layer chromatography (TLC) analysis-guided fractionation. This report describes the isolation, structure, and antifungal and cytotoxic activities of $\mathbf{1}$ and $\mathbf{2}$.

Solid-substrate fermentation cultures of $A$. novofumigatus CBS117520 grown on rice were extracted with $\mathrm{MeOH}$, and the evaporated extract was suspended in water and extracted with ethyl acetate. The evaporated extract was partitioned with acetonitrile $(\mathrm{ACN})$ and hexane to yield an $\mathrm{ACN}$-soluble fraction. The fraction was extracted sequentially with hexane, benzene, chloroform, ethyl acetate, and $\mathrm{MeOH}$. The benzene extract was chromatographed using a Sephadex LH20 column, followed by medium pressure liquid column chromatography (MPLC) on silica gel. A positive color test with phosphomolybdic acid (5\%)-ceric acid (trace) in 5\% $\mathrm{H}_{2} \mathrm{SO}_{4}$ (orange or blue) on TLC led to the isolation of compounds. Further purification of these fractions by HPLC yielded compounds 1 ( $2 \mathrm{mg}), 2(5 \mathrm{mg})$, epi-aszonalenin A $(217 \mathrm{mg})$, and $\mathrm{C}(85 \mathrm{mg})$, which are indole derivatives, and helivolic acid $(162 \mathrm{mg})$, identified by comparison with the spectral data from reports in the literature. ${ }^{2-5)}$

The molecular formula of $\mathbf{1}$ was determined as $\mathrm{C}_{32} \mathrm{H}_{36} \mathrm{~N}_{4} \mathrm{O}_{2}$ by high resolution fast atom bombardment (HRFAB) mass spectrometry. From the sixteen peaks observed in the ${ }^{13} \mathrm{C}$-NMR spectrum, it was suggested that $\mathbf{1}$ was a dimer, which consisted of two identical partial C16 units. The presence of an amine $\mathrm{NH}$ group was deduced from broad absorption at $3420 \mathrm{~cm}^{-1}$ in the IR spectrum. The presence of a tertiary amide group was inferred from the ${ }^{13} \mathrm{C}-\mathrm{NMR}$ spectrum $(168 \mathrm{ppm})$ and broad infrared absorption at $1673 \mathrm{~cm}^{-1}$. Two methyl groups at $\delta 1.10$ (s) and $\delta 0.93$ (s), vinyl groups at $\mathrm{H}_{2}-16(\delta 5.08$ and $\delta 5.12)$ and $\mathrm{H}-15(\delta 5.92), \mathrm{CH}_{2}-\mathrm{CH}$ units at $\mathrm{H}_{2}-10(\delta 2.54$ and $\delta 2.71)$ and $\mathrm{H}-11(\delta 4.08)$, and an ortho-disubstituted phenyl ring were deduced from ${ }^{1} \mathrm{H}-{ }^{1} \mathrm{H}$ correlation spectroscopy (COSY) and heteronuclear multiple quantum correlation (HMQC) data. The results of heteronuclear multiple bond correlation (HMBC) correlations of H-4 to $\mathrm{C}-3$, and $\mathrm{H}-2$ to $\mathrm{C}-8$ and $\mathrm{C}-9$, showed a dihydroindole unit incorporating the ortho-disubstituted phenyl ring. HMBC correlations of the methyl signals at $\delta 1.10$ and $\delta 0.93$, and vinyl resonance at $\mathrm{H}_{2}-16$ showed a quaternary carbon signal (C-14) at $\delta 41.7$, giving rise to the dimethylpropenyl unit. The HMBC correlations of methyl proton signals of the dimethylpropenyl unit at $\mathrm{C}-3$ indicated that the dimethylpropenyl unit should be attached to the $\mathrm{C}-3$ of the dihydroindole unit. The gross plate structure of $\mathbf{1}$ was identical to that of amauromine (3) ${ }^{6,7)}$ However, HPLC analysis showed that 1 is different from amauromine (3); the retention time $\left(t_{\mathrm{R}}\right)$ of $\mathbf{1}$ was $8.5 \mathrm{~min}$ and that of $\mathbf{3}$ was $7.5 \mathrm{~min}$ under the same conditions. These results indicated that $\mathbf{1}$ must be a diastereomer of amauromine (3) (Fig. 2).

Nuclear Overhauser effect spectroscopy (NOESY) results also showed that the relative stereochemistry of $\mathbf{1}$ is different from that of amauromine (3) (Fig. 3). The signal for H-2 correlated with H-11 and two methyl proton signals of the dimethylpropenyl unit, and $\mathrm{H}-11$ also correlated with the two methyl proton signals. Thus, H-2, H-11, and the dimethylpropenyl unit must be on the same face of the ring system. The absolute stereochemistry of amauromine (3) has been determined by comparing the circular dichroism (CD) spectral data of amauromine derivatives and related compounds by Takase $e t \mathrm{al}^{7)}$ The CD spectra of $\mathbf{1}$ showed a positive Cotton effect at $245 \mathrm{~nm}$, almost identical to that of compound $\mathbf{5}$. Therefore, compound 1 was assumed to have the same absolute configuration at $\mathrm{C}-2, \mathrm{C}-3$, and $\mathrm{C}-11$ as $\mathbf{5}$. Thus, the absolute stereochemistry of $\mathbf{1}$ was determined from the above results (Fig. 1).

The molecular formula of $\mathbf{2}$ was determined as $\mathrm{C}_{20} \mathrm{H}_{21} \mathrm{~N}_{3} \mathrm{O}_{3}$ by high resolution electron ionization (HR-EI) mass spectrometry. The UV, IR, ${ }^{1} \mathrm{H}-$ and ${ }^{13} \mathrm{C}-\mathrm{NMR}$ spectra, COSY, HMQC and HMBC data of $\mathbf{2}$ were identical to those of cycloechinulin (4), which was isolated from the fungus Aspergillus ochraceus. ${ }^{8)}$ However, the optical rotation in $\mathbf{2}$ showed that it was opposite that of $\mathbf{4}$. Furthermore, the acid hydrolysis of $\mathbf{2}$, followed by derivatization using 1-fluoro2,4-dinitrophenyl-5-L-alanine-amide (Marfey's reagent) ${ }^{9,10}$ and HPLC comparison to alanine standards indicated that the 


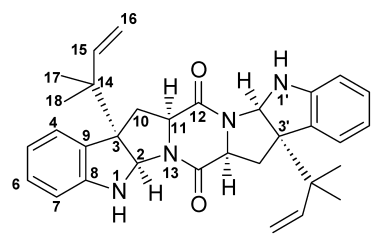

Novoamauromine (1)

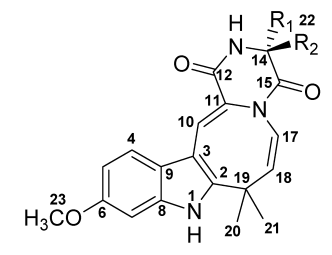

ent-Cycloechinulin (2); $\mathrm{R}_{1}=\mathrm{CH}_{3}, \mathrm{R}_{2}=\mathrm{H}$
Cycloechinulin (4) $; \mathrm{R}_{1}=\mathrm{H}, \mathrm{R}_{2}=\mathrm{CH}_{3}$

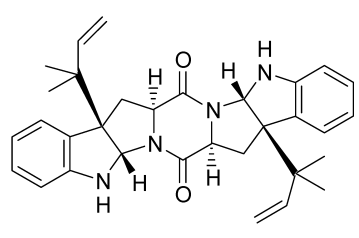

Amauromine (3)

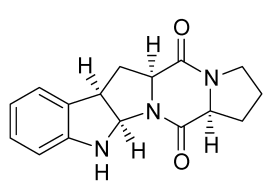

(5)
Fig. 1. Structures of Compounds $\mathbf{1}-\mathbf{5}$

alanyl residue obtained as the degradation product had $\mathrm{D}$ configuration. From the above results, it was determined that the $\mathrm{C}-14$ position in $\mathbf{2}$ has $R$ configuration, and $\mathbf{2}$ is an enantiomer of 4 (Fig. 1).

Antifungal activity was studied using the paper disk method, as described previously. ${ }^{11)}$ Novoamauromine (1) and ent-cycloechinulin (2) showed non-specific antifungal activities against Aspergillus fumigatus, A. niger, Candida albicans, and Cryptococcus neoformans, at $100 \mu \mathrm{g}$ per disk. Compounds $\mathbf{1}$ and $\mathbf{2}$ were tested for cytotoxic activities against A549 human lung cancer cells, Hela human cervical cancer cells, and LNCap human prostate adenocarcinoma cells. Compound 1 inhibited the cell proliferation of A549, Hela, and LNCap with $\mathrm{IC}_{50}$ values of 97.4, 70.0, and $94.6 \mu \mathrm{m}$, respectively. Compound $\mathbf{2}$ did not inhibit cell proliferation at $100 \mu \mathrm{M}$.

We succeeded in isolating new amauromine and cycloechinulin analogs $\mathbf{1} \mathbf{- 2}$ from $A$. novofumigatus. Their stereochemistries are different from those of $\mathbf{3}$ and $\mathbf{4}$, which were already isolated from other fungi. Furthermore, only the isolation of epi-aszonalenin $\mathrm{A}-\mathrm{C}$ from $A$. novofumigatus ${ }^{2)}$ has been reported; therefore, this fungus appears to have a specific biosynthesis different from other cyclic dipeptide analogue-producing fungi. Recently, Yin et al. have reported the biosynthesis of an aszonalenin and its derivatives from $\mathrm{A}$. $\mathrm{fu}$ migatus and Neosartorya fischeri, and described the stereo specific features as a cis-configuration between the two fivemembered rings. ${ }^{12-14)}$ We hope that further investigations in the near future will reveal new information about the stereo specific biosynthesis.

\section{Experimental}

General Melting points were determined on a micro-melting point apparatus (Yanagimoto Ltd., Kyoto, Japan), and are uncorrected. FAB-MS and EI-MS data were measured using a JMS-MS700 and a JMS-MS600W spectrometer (JEOL Co., Ltd., Tokyo, Japan), respectively. UV and IR spectra were recorded on an Ultrospec 2100 pro UV-visible spectrophotometer (Amersham Biosciences Ltd., Tokyo, Japan) and a FT/IR-4100 instrument (JASCO Co. Ltd.), respectively. ${ }^{1} \mathrm{H}-$ and ${ }^{13} \mathrm{C}-\mathrm{NMR}$ spectra were recorded using an AVANCE-400 spectrometer $\left(400.13 \mathrm{MHz}\right.$ for ${ }^{1} \mathrm{H}, 100.61 \mathrm{MHz}$ for ${ }^{13} \mathrm{C}$, Bruker Biospin K. K., Kanagawa, Japan). Chemical shifts $(\delta)$ were measured in ppm using tetramethylsilane as an internal standard. Circular dichroism (CD) curves were determined on a J-820 spectropolarimeter

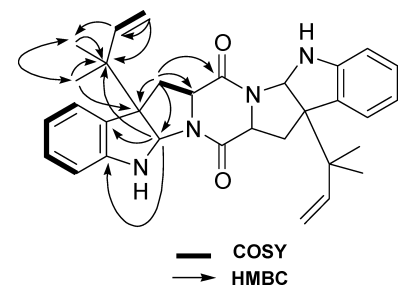

Fig. 2. Important COSY and HMBC Correlations of Novoamauromine (1)

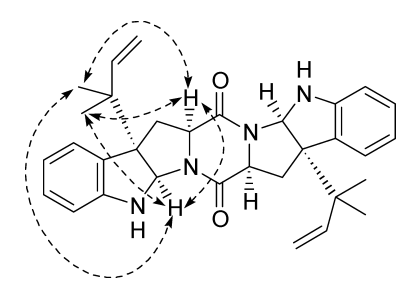

Fig. 3. Important NOESY Correlations of Novoamauromine (1)

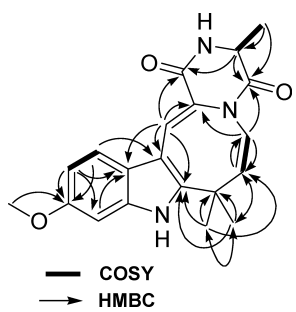

Fig. 4. Important COSY and HMBC Correlations of ent-Cycloechinulin (2)

(JASCO Co., Ltd.). Optical rotations were measured with a P-1020 photopolarimeter (JASCO Co., Ltd.). TLC was visualized by UV light at $254 \mathrm{~nm}$, and/or by spraying with phosphomolybdic acid (5\%)-ceric acid (trace) in 5\% $\mathrm{H}_{2} \mathrm{SO}_{4}$ and then heating. Column chromatography was performed using a Sephadex LH-20 (GE Healthcare Bio-Science AB, Uppsala, Sweden). MPLC was performed using a Chemco Low-Prep 81-M-2 pump (Chemco Scientific Co., Ltd., Osaka, Japan) and an ULTRA PACK SI-40B column $(300 \times 26 \mathrm{~mm}$, Yamazen Corp., Osaka, Japan). HPLC was performed using a Senshu SSC-3160 pump (flow rate $4 \mathrm{ml} / \mathrm{min}$, Senshu Scientific Co., Ltd., Tokyo, Japan) and a YMC-Pack PEGASIL Silica 60-5 column $(300 \times 10 \mathrm{~mm}$, YMC Co., Ltd., Kyoto, Japan), equipped with a YRD-883 RI detector (Shimamuratech Ltd., Tokyo, Japan). HPLC analytical conditions for novoamauromine (1) and amauromine (3) were as follows: column, a YMCPack PEGASIL Silica 60-5 column $(300 \times 10 \mathrm{~mm}$, YMC Co., Ltd.); mobile phase, $n$-hexane-acetone $(3: 1)$; room temperature; flow rate, $4.0 \mathrm{ml} / \mathrm{min}$; detector, a YRD-883 RI detector (Shimamuratech Ltd.). Amauromine (3) isolated from other fungus was used as a standard. HPLC analytical conditions for Marfey's method were as follows: column, Inertsil ODS-3, 4.6×250 mm (GL Sciences Inc., Tokyo, Japan); mobile phase, $\mathrm{CH}_{3} \mathrm{CN}-0.1 \%$ trifluoroacetic acid (TFA) $(50: 50)$; flow rate, $1.0 \mathrm{ml} / \mathrm{min}$; column oven temperature at $40^{\circ} \mathrm{C}$; detector, MD-2010 PLUS photodiode array (JASCO Co., Ltd.).

Isolation of Metabolites from Aspergillus novofumigatus CBS117520 Polished rice (Akitakomachi, $24 \mathrm{~kg}$ ) was soaked in water for $30 \mathrm{~min}$ and then sterilized with an autoclave. A. novofumigatus CBS117520 was cultivated for $14 \mathrm{~d}$ in Roux flasks, each containing $140 \mathrm{~g}$ of moist rice. The cultivated rice was extracted with $\mathrm{MeOH}$, and the extract was concentrated in vacuo. The residue was suspended in water and extracted with ethyl acetate. The EtOAc extract $(52.3 \mathrm{~g})$ was partitioned between hexane and acetonitrile to yield an acetonitrile-soluble mixture. The acetonitrile extract $(29.4 \mathrm{~g})$ was extracted sequentially with hexane $(100 \mathrm{ml})$, benzene $(100 \mathrm{ml})$, chloroform $(100 \mathrm{ml})$, ethyl acetate, and $\mathrm{MeOH}(100 \mathrm{ml})$. The benzene extract $(18 \mathrm{~g})$ was chromatographed using a Sephadex LH-20 column [solvent system: $n$-hexane $/ \mathrm{CHCl}_{3}$ (1:4) (180 ml), $\mathrm{CHCl}_{3} /$ acetone $(3: 2)$ (220 ml), (1:4) $(200 \mathrm{ml})$, acetone $(200 \mathrm{ml})$, and $\mathrm{MeOH}(500 \mathrm{ml})]$ to yield five fractions. Fraction $2\left[\mathrm{CHCl}_{3}\right.$ /acetone $(3: 2)$ eluate] was rechromatographed using 
Table $1 .{ }^{13} \mathrm{C}$ - and ${ }^{1} \mathrm{H}-\mathrm{NMR}$ Data of Novoamauromine (1) and entCycloechinulin (2)

\begin{tabular}{|c|c|c|c|c|c|c|}
\hline \multirow{2}{*}{$\begin{array}{c}\text { Carbon } \\
\text { No. }\end{array}$} & \multicolumn{3}{|c|}{ Novoamauromine (1) } & \multicolumn{3}{|c|}{ ent-Cycloechinulin (2) } \\
\hline & ${ }^{13} \mathrm{C}$ & ${ }^{1} \mathrm{H}$ & $J(\mathrm{~Hz})$ & ${ }^{13} \mathrm{C}$ & ${ }^{1} \mathrm{H}$ & $J(\mathrm{~Hz})$ \\
\hline $1-\mathrm{NH}$ & & & & & $8.29 \mathrm{brs}$ & \\
\hline 2 & 79.3 & $5.27 \mathrm{~s}$ & & 146.0 & & \\
\hline 3 & 62.5 & & & 105.3 & & \\
\hline 4 & 125.6 & $7.12 \mathrm{~d}$ & 7.5 & 118.3 & $7.67 \mathrm{~d}$ & 8.7 \\
\hline 5 & 118.6 & $6.69 \mathrm{dt}$ & $0.7,7.5$ & 110.6 & $6.83 \mathrm{dt}$ & $2.1,8.7$ \\
\hline 6 & 128.5 & $7.01 \mathrm{dt}$ & $0.7,7.6$ & 156.6 & & \\
\hline 7 & 109.6 & $6.31 \mathrm{~d}$ & 7.6 & 95.0 & $6.84 \mathrm{~d}$ & 2.1 \\
\hline 8 & 148.5 & & & 134.2 & & \\
\hline 9 & 130.7 & & & 124.3 & & \\
\hline 10 & 34.8 & $\begin{array}{l}2.54 \mathrm{dd} \\
2.71 \mathrm{dd}\end{array}$ & $\begin{array}{l}7.3,13.8 \\
9.3,13.8\end{array}$ & 115.3 & $7.60 \mathrm{~s}$ & \\
\hline 11 & 59.8 & 4.08 brt & $7.3,9.3$ & 124.5 & & \\
\hline 12 & 168.3 & & & 165.1 & & \\
\hline 14 & 41.7 & & & 50.9 & $4.15 \mathrm{dq}$ & $2.3,7.0$ \\
\hline 15 & 143.9 & $5.92 \mathrm{dd}$ & $10.8,17.4$ & 167.3 & & \\
\hline 16 & 114.6 & $\begin{array}{l}5.08 \mathrm{dd} \\
5.12 \mathrm{dd}\end{array}$ & $\begin{array}{l}0.8,17.4 \\
0.8,10.8\end{array}$ & & & \\
\hline 17 & 22.5 & $0.93 \mathrm{~s}$ & & 122.0 & $5.82 \mathrm{~d}$ & 8.3 \\
\hline 18 & 22.6 & $1.10 \mathrm{~s}$ & & 139.8 & $5.94 \mathrm{~d}$ & 8.3 \\
\hline 19 & & & & 35.9 & & \\
\hline 20 & & & & 27.1 & $1.67 \mathrm{~s}$ & \\
\hline 21 & & & & 26.9 & $1.68 \mathrm{~s}$ & \\
\hline 22 & & & & 18.3 & $1.54 \mathrm{~d}$ & 7.0 \\
\hline 23 & & & & 55.6 & $3.81 \mathrm{~s}$ & \\
\hline
\end{tabular}

MPLC with a silica gel [ $n$-hexane/acetone $(2: 1)$ to acetone] to give novoamauromine (1: $2 \mathrm{mg})$, epi-aszonalenin C ( $85 \mathrm{mg}$ ), helivolic acid (162 mg), epi-aszonalenin A $(217 \mathrm{mg})$, and ent-cycloechinulin (2: $5 \mathrm{mg})$. The spectral data of epi-aszonalenin C, helivolic acid and epi-aszonalenin A were identical to those from reports in the literature.

Novoamauromine (1) Colorless amorphous solid; $[\alpha]_{\mathrm{D}}+155^{\circ}$ ( $c=0.425, \mathrm{CHCl}_{3}$ ); HR-FAB-MS obsd 509.2921, calcd for $\mathrm{C}_{32} \mathrm{H}_{37} \mathrm{~N}_{4} \mathrm{O}_{2}$ $(\mathrm{M}+\mathrm{H})^{+}$509.2917; UV $\lambda_{\max }^{\mathrm{MeOH}} \mathrm{nm}(\log \varepsilon) 205$ (4.7), 239 (4.1), 297 (3.6); IR $v_{\max }^{\mathrm{KBr}} \mathrm{cm}^{-1} 3420,1673 ; \mathrm{CD}\left(c=2.26 \times 10^{-5}, \mathrm{EtOH}\right) \Delta \varepsilon(\mathrm{nm}) 87.6(210), 25.1$ (245), 10.5 (297). The ${ }^{1} \mathrm{H}$ - and ${ }^{13} \mathrm{C}$-NMR signal assignments are summarized in Table 1

ent-Cycloechinulin (2) Yellow solid ( $\mathrm{mp} 275-277^{\circ}$, from $\mathrm{MeOH}$ ); $[\alpha]_{\mathrm{D}}+47.6^{\circ}\left(c=1.00, \mathrm{CHCl}_{3}\right)$; HR-EI-MS obsd 351.1582 , calcd for $\mathrm{C}_{20} \mathrm{H}_{21} \mathrm{~N}_{3} \mathrm{O}_{3}\left(\mathrm{M}^{+}\right)$351.1583; UV $\lambda_{\max }^{\mathrm{MeOH}} \mathrm{nm}(\log \varepsilon) 215$ (4.0), 268 (3.7), 302 (3.8), 377 (3.7); IR $v_{\max }^{\mathrm{KBr}} \mathrm{cm}^{-1} 3341$ (br), 1682, 1667; CD $\left(c=8.55 \times 10^{-5}\right.$, $\mathrm{MeOH}) \Delta \varepsilon(\mathrm{nm}) 2.5$ (206), $-5.6(227),-2.3$ (301), 3.4 (375). The ${ }^{1} \mathrm{H}-$ and ${ }^{13} \mathrm{C}$-NMR signal assignments are summarized in Table 1.

Amino Acid Analysis of ent-Cycloechinulin (2) ent-Cycloechinulin (2: $1.0 \mathrm{mg}$ ) was dissolved in $100 \mu \mathrm{l}$ of $6 \mathrm{M} \mathrm{HCl}$ and heated at $110^{\circ} \mathrm{C}$ for $16 \mathrm{~h}$. The resulting hydrolyzate was allowed to cool and then neutralized with $\mathrm{NaHCO}_{3}$. Then, $200 \mu \mathrm{l}$ of Marfey's reagent (PIERCE, IL, U.S.A.) and $40 \mu \mathrm{l}$ of $1 \mathrm{M} \mathrm{NaHCO}$ were added to this mixture, and the mixture was heated at $40^{\circ} \mathrm{C}$ for $1 \mathrm{~h} . \mathrm{HCl}(2 \mathrm{M}, 20 \mu \mathrm{l})$ was added upon cooling to room temperature. The solution was then analyzed by reversed phase HPLC, as previously described. Coinjection with D- and L-alanine standards $\left(t_{\mathrm{R}}=5.0\right.$ and $4.6 \mathrm{~min}$, respectively) indicated that the alanyl residue in $\mathbf{2}$ has D-configuration.

Antifungal Assay Using the Paper Disk Method Antifungal assay was performed using a previously reported method, ${ }^{11)}$ the paper disk method, against A. niger IFM 41398, A. fumigatus IFM 41362, C. albicans IFM
40009, and C. neoformans ATCC 90112 as test organisms. Novoamauromine (1) and ent-cycloechinulin (2) were applied to the paper disk (diameter: $8 \mathrm{~mm}$ ) at $100 \mu \mathrm{g}$ per disk and the disks were placed on assay plates. The test organisms were cultivated in potato dextrose agar (Nissui Pharmaceutical Co., Ltd., Tokyo, Japan) at $25^{\circ} \mathrm{C}$. After $48-72 \mathrm{~h}$ of incubation, the zones of inhibition (the diameter measured in millimeters) were recorded.

Cytotoxicity Assay Cytotoxicity assay was performed by a modified method of the previous paper. ${ }^{11)}$ Cells were seeded into 96-well microplates at 4000 cells per well, and allowed to attach for $4-6 \mathrm{~h}$. A549 human lung cancer cells and Hela human cervical cancer cells were then incubated in Dulbecco's modified Eagle's medium (Invitrogen Co., Ltd., Carlsbad, CA, U.S.A.), and LNCap human prostate adenocarcinoma cells in RPMI-1640 medium (Wako Pure Chemical Industries, Ltd., Osaka, Japan) supplemented with $10 \%$ fetal bovine serum, penicillin $\mathrm{G}(100 \mathrm{U} / \mathrm{ml})$, streptomycin $(100 \mu \mathrm{g} / \mathrm{ml})$ and amphotericin B $(0.25 \mu \mathrm{g} / \mathrm{ml})$ until $80 \%$ confluency. Media were supplemented with the indicated concentrations of isolated compounds for $48-72 \mathrm{~h}$. Cell proliferation was measured using the Cell Counting Kit-8 (Dojindo, Kumamoto, Japan) to count living cells by combining WST-8 (2-(2-methoxy-4-nitrophenyl)-3-(4-nitrophenyl)-5-(2,4-disulfophenyl)$2 H$-tetrazolium) and 1-methoxy PMS (1-methoxy-5-methylphenazinium methysulfate). Briefly, $10 \mu \mathrm{l}$ of Cell Counting Kit-8 solution was added to each well after the medium was removed, and the plates were incubated for $4 \mathrm{~h}$. Cell number was determined by scanning with a Bio-Rad Model Q4 550 microplate reader at $450 \mathrm{~nm}$.

Acknowledgements We are indebted to Prof. K. Takahashi, Meiji Pharmaceutical University, for the FAB-MS measurements. This work was supported by an "Open Research Center" Project from the Ministry of Education, Culture, Sports, Science and Technology, Japan, and by a Grant-in-Aid for Scientific Research (No. 20590017) from the Japan Society for the Promotion of Science. This study also was partly supported by the Cooperative Research Program of the Research Center for Pathogenic Fungi and Microbial Toxicoses, Chiba University (09-2).

\section{References}

1) Hong S.-B., Go S.-J., Shin H.-D., Frisvad J. C., Samson R. A., Mycologia, 97, 1316-1329 (2005).

2) Rank C., Phipps R. K., Harris P., Frisvad J. C., Gotfredsen C. H., Larsen T. O., Tetrahedron Lett., 47, 6099-6102 (2006).

3) Okada S., Iwasaki S., Tsuda K., Sano Y., Hata T., Udagawa S., Nakayama Y., Yamaguchi H., Chem. Pharm. Bull., 12, 121-124 (1964).

4) Fujimoto H., Negishi E., Yamaguchi K., Nishi N., Yamazaki M., Chem. Pharm. Bull., 44, 1843-1848 (1996).

5) Lee S.-Y., Kinoshita H., Ihara F., Igarashi Y., Nihira T., J. Biosci. Bioeng., 105, 476-480 (2008).

6) Takase S., Kawai Y., Uchida I., Tanaka H., Aoki H., Tetrahedron Lett., 25, 4673-4676 (1984)

7) Takase S., Kawai Y., Uchida I., Tanaka H., Aoki H., Tetrahedron, 41, 3037-3048 (1985)

8) Guzman F. S., Gloer J. B., Wicklow D. T., Dowd P. F., J. Nat. Prod., 55, 931-939 (1992).

9) Marfey P., Ottesen M., Carlsberg Res. Comm., 49, 585-590 (1984).

10) Marfey P., Carlsberg Res. Commun., 49, 591-596 (1984).

11) Wakana D., Hosoe T., Wachi H., Itabashi T., Fukushima K., Yaguchi T., Kawai K., J. Antibiot., 62, 217-219 (2009).

12) Yin W.-B., Cheng J., Li S.-M., Org. Biomol. Chem., 7, 2202-2207 (2009).

13) Yin W.-B., Grundmann A., Cheng J., Li S.-M., J. Biol. Chem., 284, 100-109 (2009).

14) Ruan H.-L., Yin W. B., Wu J. Z., Li S.-M., ChemBioChem, 9, 1044 1047 (2008). 